Int. J. Electrochem. Sci., 15 (2020) $1982-1995$

\title{
Nitrogen-doped Oxygen-rich Activated Carbon Derived from Longan Shell for Supercapacitors
}

\author{
Ji Yan ${ }^{1,2, *}$, Ya-Yong Fang ${ }^{1}$, Shi-Wen Wang ${ }^{1}$, Shi-De Wu ${ }^{2, *}$, Li-Xia Wang ${ }^{1}$, Yong Zhang ${ }^{1}$, \\ $\mathrm{He}$-Wei Luo ${ }^{1}$, Yang Cao ${ }^{1}$, Hai-Li Gao ${ }^{1}$, Li-Zhen Wang ${ }^{2}$, Fu-Jun Liu ${ }^{3, *}$ \\ ${ }^{1}$ School of Materials and Chemical Engineering, Zhengzhou University of Light Industry, Zhengzhou \\ 450001, Henan, PR China \\ ${ }^{2}$ Henan Provincial Key Laboratory of Surface Interface Science, Zhengzhou University of Light \\ Industry, Zhengzhou, 450001, Henan, PR China \\ ${ }^{3}$ Instituto de Fisica, Universidade de Brasilia, 70910-900 Brasilia, DF, Brazil \\ *E-mail: jiyan@zzuli.edu.cn (Dr.J.Yan), sdwu@zzuli.edu.cn (Prof. S.D.Wu), fliu@unb.br (Dr. F.J. \\ Liu).
}

doi: $10.20964 / 2020.03 .18$

Received: 4 October 2019 / Accepted: 9 December 2019 / Published: 10 February 2020

In this study, longan shell as biowaste material has been collected to prepare activated carbon for supercapacitors. The biochar was firstly carbonized and then etched by KOH to transform into porous carbon architecture. With the help of XRD, SEM, Raman and XPS, physical and chemical properties of the samples were investigated and the optimized parameters of preparation is the etching ratio of 1:2 at pre-carbonization temperature of $500{ }^{\circ} \mathrm{C}$ following the etching temperature at $700{ }^{\circ} \mathrm{C}$. Due to the nitrogen-doping carbon combined with oxygen-rich functional groups as well in-situ $\mathrm{CaCO}_{3}$ template, the achieved activated carbon possesses a specific capacitance of $210 \mathrm{~F} \mathrm{~g} \mathrm{~g}^{-1}$ at a current density of $0.5 \mathrm{~A}$ $\mathrm{g}^{-1}$, with a moderate rate capability at $20 \mathrm{~A} \mathrm{~g}^{-1}$. Symmetrical supercapacitor has also been assembled and its power density reaches $17.2 \mathrm{Wh} \mathrm{kg}^{-1}$ at energy density of $1,000 \mathrm{~W} \mathrm{~kg}^{-1}$ with a high capacitance retention of $68.3 \%$ from $1 \mathrm{~A} \mathrm{~g}^{-1}$ to $40 \mathrm{~A} \mathrm{~g}^{-1}$. After tested at $4 \mathrm{~A} \mathrm{~g}^{-1}$ for 10,000 cycles, the capacitor only shows slightly capacitance decay with the retention almost $100 \%$, demonstrating a practical application value in supercapacitors.

Keywords: Bio-waste derived; Activated carbon; Nitrogen-doped; Electrochemical capacitors;

\section{FULL TEXT}

(C) 2020 The Authors. Published by ESG (www.electrochemsci.org). This article is an open access article distributed under the terms and conditions of the Creative Commons Attribution license (http://creativecommons.org/licenses/by/4.0/). 